\title{
Discussion on Application of the Garment Industry Logistics Informatization
}

\author{
Wei-Xia Yang \\ Business of Xian International University, Xi'an, China \\ wxyang741117@163.com
}

Keywords: Garment industry, Informatization, Technology.

\begin{abstract}
China is the largest garment consumption. The garment industry has become an important part of our national economy, and it is closely related with people's life, consumption, production. It is an important reflection of development in economic and social. But with the deepening of economic globalization, production and supply of garment enterprises began to compete in the same industry chain, the information collection, exchange, reaction of the supply chain has become a key factor to improve the competitiveness of enterprise. Whose information of supply chain timely, accurately, effectively transfer between node enterprises will be able to win in the competition. In the paper, the author analyzes problems about our country enterprise construction and the characteristics of logistics informationization, combing with Chinese garment industry reality environment and the special situation of garment industry. Finally the author puts forward a series of garment industry informatization strategy, to break the bottleneck and improve the rapid response to market demand.
\end{abstract}

\section{Introduction}

With growing competition, the competition between enterprises has become competition between supply chains, so information between the link enterprises in the supply chain has become the key factor of competition. The supply chain where information delivered timely, accurately, effectively between the link enterprises, will be able to win in the competition; conversely, if information of the supply chain is not timely transferred between enterprises, or is distorted during the process of transferring, it will lead to decline the competitiveness of the supply chain, until the enterprises will be eliminated by the market. Among of many kinds of information in the supply chain, logistics information plays an important role in supply chain decision of enterprise. [1] For garment enterprises, although requirement of each enterprise to the logistics system is not the same, but the solution is always logistics management informatization. Because the logistics information play a important role not only in connecting the production enterprises, wholesalers, retailers, and consumers, but also in realizing the whole of the supply chain efficiency based on making full use of modern information technology. Therefore, the development of logistics informatization of clothing enterprises is a good choice.

\section{Concept and Characteristic of Garment Enterprises Logistics Information}

\section{Concept of garment enterprises logistics information}

By the "garment enterprises logistics information" we mean the information that associated with the clothing enterprise logistics activities, such as transportation tools selection, transportation route determination, each shipping fee determination, tracking goods in transit, the effective use of the warehouse, determine the best stocks, order management, how to improve the level of customer service, and so on. From the broad perspective, logistics information includes not only information related with the logistics activities, but also information related with other circulation activities, such as commodity trading information, market information and policy information.

\section{Characteristic of garment enterprises logistics information}

With the development of the logistics industry and its related technologies, information technology is playing the crucial role in modern logistics. Informalization has become the basic guarantee of 
performance in logistics system and a major symbol of the modern logistics. [2] Compared with other enterprises, clothing enterprise logistics information has the following characteristics:

\section{Limitless variety}

Every joint of logistics activities will originate a variety of logistics information, including not only the internal logistics information of clothing enterprise, but also including logistics information between clothing enterprises and cooperation enterprises and information of infrastructure associated with logistics activities. Sources, processing locations and diffusion range of various logistics information are different, which makes the amount work in classification,collection and statistical analysis of logistics information increase.

\section{Abundant information \\ With the launch of logistics activities and commodity trading Logistics information occurs on a large scale.With the development of personalized consumption characteristics, logistics information of multi-variety and small batch production and multiple frequency small number distribution inventory, transportation surged.}

\section{Astonish speed}

First of all, update speed of garment enterprise logistics information is fast. That including many varieties of small batch production, the frequent small number distribution, and using sale information system of instant sales point make all kinds of activities occur frequently, which requires the logistics information update, but update speed faster and faster.

Secondly, transmission speed of the logistics information is fast, modern technology represented by multimedia electronic computer has a great influence on all aspects of social progress and economic development, the influence on logistics information management reflect greatly improving the transmission speed of logistics information, promoting the logistics information management efficiency. [3]

Finally, the attenuation speed of the value of logistics information is fast. The dynamic of logistics information is strong, the attenuation speed of the value is fast, which required the timelinessments of logistics information management will be improved.

\section{Reproducibility}

Firstly, clothing enterprise informatization system has to be flexible, to meet the diverse needs of the system users and the customer. Secondly, clothing enterprise informat-ion system must have the ability of providing all kinds of data and information to meet specific cust-omer needs, but also the information can continue to expand and regeneration in the process of logistics. This means that in the whole process of logistics, data consolidation, analysis and create information,information association, reasoning and draw some useful conclusions, generate two information. [4]At the same time, through the analysis of logistics information, history information combined with present situation forecast the trend of logistics industry in the future, produce three information. By using the regeneration of logistics information, clothing enterprises managers can improve the efficiency of logistics management and level of decision-making.

\section{The Operation Status Quo of the Application of Garment Enterprises Logistics Informatization}

\section{Management concepts of logistics informatization is backward}

Most of chinese garment enterprises are small scale enterprises, their management is relatively weak. The application of the concept and practice of logistics informatization management in China's garment enterprises is still in its primary stage. In recent years, the management of clothing enterprises has been increasingly improved the recognition of the importance of logistics informatization construction, but for most of the clothing enterprises, some of them can not understand the concept of informatization perfectly well, some of them has certain understand the application of logistics informatization, but the 
single application of informatization is more, they have not realize the importance of integrated information and information sharing. [5]

\section{Consciousness of logistics informatization is weak}

For clothing enterprise, the product is single, the business is simple, but the task of informatization management is arduous. Documents needed statistics is very large in every day, it requires garment enterprises to speed up the construction of informatization. But now many clothing enterprises are busy to grab the market, did not give attention to logistics informatization construction. The conscsniouess of informatization is not rooted in the mind of management. They are not aware that the current market economy is the information economy, and enterprises should highly depend on information, all the competitive strategy and tactics should be based on information. So in the process of enterprise informatization development,there is no professional programes the appliation of the logistics informatization, there is no professional collect and file logistics informatization. So transmission speed of the informatization is slow, the enterprise cannot make a correct prediction to changes in the market, and it can caused the loss to the enterprise.

\section{Unified planning and standard of application of logistics informatization technology is lack}

For garment enterprises, there is no unified planning and standards in the construction of logistics informatization, such as the lack of enterprise standard and coercive measures of logistics informatization technology, these affect the application of garment enterprises logistics informatization. [6] Products of many enterprises only stay in the intermediate links in circulation, inventory and cash flow has seriously restricted the development of enterprises. Update speed of informatization technology is rapid, emergence speed of new products and new technology is rapid, these cause that some standard just launched gets behind, this is the reason that uniform standards is lack .

\section{Analysis of the Problems in the Application of Logistics Informationization Garment Enterprises}

\section{For garment enterprises, understanding to purpose of logistics informatization is not clear}

Many garment enterprises do not realize effects of enterprise logistics informatization on enterprises, especially do not carefully conside the fusion of enterprise logistics information and its organization,so the application of logistics informatization is certain blindness. They do not aware of the logistics informatization as a technical means into the enterprise.Many garment enterprises did not carry out the overall planning and relevant countermeasures to the logistics informationization, did not reach the aim of improving the competitiveness of enterprises. Looking from the actual effect, a simple application is more, deep application is little.[7]Application and maintenance of enterprise logistics informatization excessivly dependence on external information technology providers and consultants, the company does not develope their own information talent, not build enterprise information ability.

\section{The quality of staff is relatively low}

At present,the cultural quality of staff in our country clothing enterprise is generally lower, logistics network and management concept is lack, they used to manual operation and management, it is difficult to master advanced information technology foe them. Many personnel of clothing enterprise just master information, or just to understand the business process, which resulted in the contradiction between business and information system .

\section{Investment in logistics informatization is lack}

In the current increasing competition in the apparel market, enterprises want to win the competition, they want to not only recognize the importance of logistics information in consciousness, but also invest a lot of human and financial resources in the construction of logistics information, and this kind of investment should be long-term, only in this way can we form the capability of enterprise informatization. But because of various reasons, many enterprises are difficult to bear such a heavy burden, resulting in investment in logistics informatization lack. 


\section{Strategy of optimizing the application of logistics informatization garment enterprises}

The implementation of information management can set up a quick information feedback system of garment enterprises, thus it can greatly improve the response speed to market, reduce risk and cost of the operation, provide the integrity data of the production management for enterprise decision makers, each business links can also be combined organically, business statistical analysis can be automated.

\section{Enhance the awareness of logistics informatization construction}

Awareness trumps everything, no improving awareness is not possible to cause positive action, and it will also be impossible to achieve good results. In view of the deficiency of the knowledge of information for many small and medium-sized enterprises, the government must adopt many kinds of forms, carry out the multi-level information knowledge propaganda, training and promotion through various channels. Especially the government should strengthen training of informatization knowledge to small and medium-sized enterprises in backward areas and the traditional labor-intensive small and medium-sized enterprise, increase the information knowledge of enterprises, raise the level of awareness of enterprises, strengthen information consciousness of enterprises, stimulate demand for informatization of enterprise.

\section{Training of technical personnel}

In the era of knowledge economy, it has become a pressing matter that rapidly improving the overall quality of enterprises. Clothing enterprise decision-making layer, costume designer should timely grasp the development trend of consumer psychology and market, and should have the ability of collecting information and solveing problem. Clothing sales, technology, production management personnel should possess the knowledge of information network, and have the rich innovation consciousness, the keen judgment insight and rich imagination, and must constantly update their knowledge. On one hand ,government must support education, on the other hand, enterprises need to cultivate the existing personnel becoming the professional logistics personnel.

\section{Introducing logistics informatization system}

Logistics informatization construction is more widely attention and development in a number of large-scale clothing enterprises, some small and medium-sized garment enterprises is relatively slow in the construction of logistics informatization due to lack of funds, However, the development of informatization technology and internet has brought new opportunities for the development of the construction of logistics enterprises informatization. It is necessary to increase the investment in introducing advanced logistics information system, to unified planning and standard of logistics information between enterprises.

\section{References}

[1] Tu Yu Long, “Analysis Countermeasure of Enterprise's Logistics Information Construction”, Modern Business, No.2, Pp.34-35, 2008.

[2] Zhao Yang, "the third Party Logistics Enterprise Customer Relationship Management", Operation and Management, no. 8, pp.57-59, 2010.

[3] Ji Lei, "the Third Party Logistics Enterprise Customer Relationship Management”, Operation and Management, no. 6, pp.63-65, 2011.

[4] Wu Hui Jie, "Modern Logistics Enterprises customer Relationship Management”, Enterprise, no. 5, pp.245-247, 2011.

[5] Gong Xian Wen, "Explore on the Customer Alienation Service Strategy of Third Party Logistics Enterprise", Journal of Chongqing Education College, no. 3, pp.33-36, 2011.

[6] Yu Miao, "Research on Implementation of the Third Party Logistics Enterprises Important Customer Relationship Management”, Management Engineer, no. 1, pp.63-65, 2010.

[7] Hou Chun-Lan, “Analyze On The Important Role Of Internal Supply Chain Management In Modern Business Administration”, Modern Information Economy, no.6, pp.24-29, 2012. 